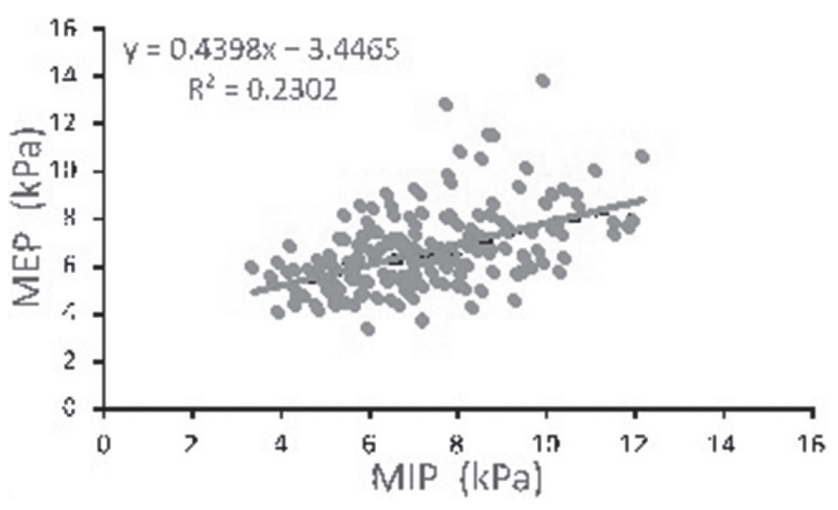

Abstract P256 Figure 1 MIP vs MEP (regression analysis $p=0.004$ )

\section{P257 UNDERSTANDING THE EFFECTS ON LUNG FUNCTION OF CHEST BINDER USE IN THE TRANSGENDER POPULATION}

${ }^{1} \mathrm{RJM}$ Cumming, ${ }^{2} \mathrm{~K}$ Sylvester, ${ }^{2} \mathrm{~J}$ Fuld. 'University of Cambridge, Cambridge, UK; ${ }^{2}$ Addenbrookes Hospital, Cambridge, UK

\subsection{6/thoraxjnl-2016-209333.400}

Introduction Chest binders are garments used for compression of breast tissue by transgender individuals. Deleterious consequences of binder reported include shortness of breath with associated reduced exercise tolerance and speech difficulties; some have suggested lung function is monitored in users of chest binders. ${ }^{1}$ We conducted a study to investigate any respiratory deficits caused by chest binders as currently used in the transgender population. Methods We recruited 20 participants from the transgender community. All were assigned female at birth. Ages ranged from 1947 with median age 22; 4 were current smokers and 4 had mild to moderate asthma. All were habitual users of chest binders. Participants underwent spirometry testing and measures of chest circumference and posture with and without their own binder. The order of testing with or without the binder was random. Ethics approval was granted by the University of Cambridge.

Results Table 1 shows abnormal baseline lung function. The median FEV1/FVC is abnormally high but not acutely influenced by the binder. The standard residual of all forced spirometric values was significantly $(\mathrm{p}<0.001)$ below predicted values (based on sex assigned at birth); peak expiratory flow (PEF) values were also lower than predicted. There was a significant reduction in expiratory vital capacities, both SVC and FVC $(p<0.01)$ when the binder was on but no other significant acute change. On average chest circumference was reduced by the binder. There was no average change in thoracic kyphosis due to high variability.

Conclusions Transgender individuals using chest binders have abnormal lung function. The acute effect of wearing the binder appears to be an overall volume reduction with little other change. Abnormal lung function in the population may indicate a chronic effect of binder usage or generally poor respiratory health. However, due to the small size and timeframe of the study no control population was tested and thus a systematic error cannot be ruled out.
Abstract P257 Table 1 Median spirometry values acquired with the binder off vs. on. A reduction in vital capacity is seen with the binder on.

\begin{tabular}{|c|c|c|c|c|c|c|c|c|c|c|}
\hline & \multicolumn{10}{|c|}{ Summary of spirometry values } \\
\hline & \multicolumn{2}{|l|}{ FVC } & \multicolumn{2}{|l|}{ FEV1 } & \multicolumn{2}{|c|}{ FEV1/FVC } & \multicolumn{2}{|l|}{ PEF } & \multicolumn{2}{|l|}{ SVC } \\
\hline & Off & On & Off & On & Off & On & Off & On & Off & On \\
\hline $\begin{array}{l}\text { Median } \\
\text { (litres) }\end{array}$ & 4.35 & 4.29 & 3.46 & 3.53 & 0.82 & 0.82 & 394.2 & 397.2 & 4.22 & 4.12 \\
\hline $\begin{array}{l}\text { Median } \\
\text { (SR) }\end{array}$ & -0.54 & -0.65 & -0.92 & -1.30 & -0.62 & -0.46 & & & & \\
\hline $\begin{array}{l}\text { Median } \\
\text { (\% Pred.) }\end{array}$ & & & & & & & 87.7 & 87.0 & & \\
\hline $\begin{array}{l}p \text { value } \\
\text { off vs on }\end{array}$ & 0.0062 & & 0.0701 & & 0.3603 & & 0.2349 & & 0.0008 & \\
\hline
\end{tabular}

\section{REFERENCE}

1 Davies S, Papp VG, Antoni C. Voice and communication change for gender nonconforming individuals: Giving voice to the person inside. Int J Transgenderism 2015;16:117-159.

\section{P258 INFANT LUNG FUNCTION TESTING: A NEW APPROACH USING A RAPID, PORTABLE SYSTEM FOR MEASURING LUNG CLEARANCE INDEX (LCI) IN HEALTH AND DISEASE}

${ }^{1}$ A Shawcross, ${ }^{1} \mathrm{CS}$ Murray, ${ }^{2} \mathrm{~J}$ Kirkby, ${ }^{3} \mathrm{~J}$ Miles, ${ }^{2} \mathrm{~K}$ Pike, ${ }^{3} \mathrm{~S}$ Rees, ${ }^{2} \mathrm{P}$ Aurora, ${ }^{1} \mathrm{~A}$ Horsley. 'University of Manchester, Centre for Respiratory Medicine and Allergy, Manchester, UK; ${ }^{2}$ Respiratory, Critical Care and Anaesthesia Section, Institute of Child Health, UCL, London, UK; ${ }^{3}$ Lung Function Unit, Great Ormond Street Hospital for Children, London, UK

\subsection{6/thoraxjnl-2016-209333.401}

Introduction Lung clearance index (LCI) is a sensitive measure of lung disease in infants, with potential applications in clinical practice and research. However, measuring LCI in infants is technically challenging and there is no simple method of assessing LCI outside of specialist research laboratories in this population.

We have previously described an alternative method of measuring LCI, in which expired gas is collected and analysed to derive functional residual capacity (FRC) and LCI without directly measuring flow. This eliminates one of the major technical challenges, whilst also reducing the system's dead space. This method is highly accurate in vitro, with a mean accuracy of FRC measurement to within $1 \%$, down to FRC of $100 \mathrm{ml} .{ }^{1}$ The method does not require large external gas tanks, and washout is performed breathing room air, making the system fully portable.

Aim To assess the performance of this method in vivo.

Method Healthy controls and infants with CF are currently being recruited to undergo LCI measurement using this method. Practical applicability of the system is determined by the number of successful tests and within-subject repeatability, defined as coefficient of variation (CV\%) of same-visit repeats. Comparison will be made with LCI measurements obtained using a respiratory mass spectrometer, currently considered the gold standard for infant LCI measurement. 
Results To date, 10 healthy controls (mean age 53 weeks) and 2 infants with CF (mean age 55 weeks) have successfully undergone LCI measurement using this method. Mean LCI in controls was 6.62 (range 5.79-7.91). Mean within-subject CV\% was 5.9\%. Mean LCI in infants with CF was 7.63 (CV 5\%).

Conclusion Preliminary data suggest this is a feasible and reproducible method of performing LCI in infants. Results in both infants with $\mathrm{CF}$ and controls fall within ranges predicted by the respiratory mass spectrometer ${ }^{2}$ and within accuracy limits set by international guidelines. This could provide a more accessible alternative to current technologies, enabling this test to be offered in more centres.

\section{REFERENCES}

1 Shawcross, et al. Ped Pulmonol 2016:51:491-497.

2 Lum, et al. Eur Respir J 2013;41:1371-7.

\section{P259 COST ANALYSIS OF IMPLEMENTING A PE PATHWAY INCORPORATING 3-LEVEL WELLS SCORING, PERC RULES AND AGE-ADJUSTED D-DIMERS}

A Mahmood, C Durrans, S Naik, M Anwar. Princess Alexandra Hospital, Harlow, UK

10.1136/thoraxjnl-2016-209333.402

Background Acute pulmonary embolism (PE) is a common presentation. Currently NICE recommends 2-level Well scoring, which may over-investigate patients leading to unnecessary anticoagulation and contrast-related risks and significant financial costs. We investigated whether further risk stratification using a combination of 3-level Wells scoring, PERC rules and ageadjusted D-dimers could minimise costs and enhance patient safety.

Methods Retrospective analysis of patients who underwent CTPA and had complete data between September 2014 and August 2015 was carried out. Wells scores, PERC scores and ageadjusted D-dimers were calculated and compared against CTPA findings.

Results Out of 1174 patients who underwent CTPA, 1158 had complete data set. Application of PERC rules to low-risk patients (Wells score $0-1 ; \mathrm{n}=311,27 \%$ ) would have avoided 64 CTPAs, but missed 3 PEs, with a 95\% sensitivity (95\% CI: 0.85-0.97), 24\% specificity (95\% CI: 0.19-0.30), and avoided 56 D-dimers.

For intermediate-risk patients (Wells score 2-7), age-adjusted D-dimers would have avoided 265 CTPAs but missed 32 PEs, with an $81 \%$ sensitivity (95\% CI: 0.74-0.86), 50\% specificity (95\% CI: $0.45-0.55)$. High-risk patients should proceed directly to CTPA.

The combination of 3-level Wells scoring, PERC rules, and age-adjusted D-dimers would have avoided 450 CTPAs (39\%) but missed 39 PEs (8\%), with an estimated financial saving of at least $£ 255,150$ (local CTPA tariff $£ 567$ ). Non-age adjusted Ddimers would have reduced this avoiding 132 CTPAs (11\%), and missing only 7 PEs (5\%). Further saving would have resulted from avoiding D-dimer testing in low risk PERC negative patients, and high risk patients.

Conclusion The use of a PE algorithm incorporating multiple clinical assessment tools results in a pathway which can help rationalise the number of CTPAs performed and D-dimers requested, without significantly increasing the proportion of missed PEs.

\section{REFERENCES}

1 Forciea MA, et al. Evaluation of patients with suspected acute pulmonary embolism: best practice advice from the clinical guidelines committee of the American College of Physicians. Ann Intern Med 2015;163(9):701-11.

2 Singh $B$, et al. Pulmonary embolism rule-out criteria (PERC) in pulmonary embolism-revisited: a systematic review and meta-analysis. Emerg Med J 2013;30 (9):701-6.

\section{Pneumonia and Bronchiectasis: Why Fore and Where to}

\section{P260 THE UTILITY OF ATYPICAL PNEUMONIA SCREENING IN COMMUNITY ACQUIRED PNEUMONIA: THE LEICESTER EXPERIENCE}

JA Bennett, S Robinson, R Rupesinge, J Skeemer, D Jenkins, G Woltmann. Glenfield Hospital, Leicester, UK

\subsection{6/thoraxjnl-2016-209333.403}

Introduction Microbiological testing for atypical pathogens in patients attending hospital with community acquired pneumonia (CAP) is recommended for moderate or severe disease (NICE CG191 2014) or for patients failing to respond to treatment. Although it is unclear whether testing improves outcome even in severe disease, many patients have such tests performed regardless of severity. Having revised our pathways for assessment, treatment and documentation of patients with community acquired pneumonia we hypothesised that testing for atypical organisms has no impact on treatment decisions for these patients.

Method We retrospectively identified all patients with a diagnosis of CAP who had investigations for atypical microbiology, September 2013 to May 2014, via our pneumonia database. We assessed CURB-65 score, atypical microbiology results and laboratory costings. The notes for all patients with positive atypical microbiological results were reviewed.

Results 343 patients were identified for whom 329 were analysed.

329 patients generated 991 samples in total (825 serum, 165 urine antigen, 1 urine virology) at a laboratory cost of $£ 5,594.29$.

Five samples were positive, one for urine legionella antigen.

Greater than $50 \%$ of serological samples had no second (paired) sample sent.

There was no correlation between CURB-65 scores and requesting of atypical microbiology requesting.

One patient with positive legionella antigen had prolongation of treatment from 5 days to 14 days.

No other patients had treatment changes as a consequence of atypical microbiological testing.

Conclusion Atypical microbiological testing, in hospital, for CAP patients is commonly performed at significant cost with minimal clinical utility. We recommend that non-selective serological sampling is abandoned. The impact of legionella urinary antigen testing on outcome in moderate and severe cases requires a prospective study. 